\title{
Prevalence of Skin Diseases in Rural Kashmir: A community Based Survey
}

\author{
Mubashar Mashqoor Mir ${ }^{1}$ and Mohammad Sarwar Mir ${ }^{2 *}$ \\ ${ }^{1}$ Post Graduate Resident, Department of Dermatology, Government Medical College, India \\ ${ }^{2}$ Senior Resident, Department of Hospital Administration, SKIMS, India \\ *Corresponding author: Mohammad Sarwar Mir, Senior Resident, Department of Hospital Administration, SKIMS, Srinagar, India
}

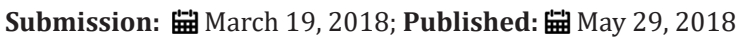

\begin{abstract}
Introduction: Skin diseases are one of the most common health problems. The objectives of this study are to determine the prevalence of skin diseases in a rural community.

Methods: A community survey was conducted in a rural locality with 2000 inhabitants, to obtain socio-demographic data and identify individuals with skin diseases.

Results: Of 600 individuals attending the health camps, had one or more Skin diseases. The overall prevalence of SDs was 22.5\%.The most common SD categories were eczemas, fungal infection, pigment disorders and acne. The prevalence of the diseases was higher in females. The children were the most common group affected.

Conclusion: This population-based study shows that Skin diseases are very common in a rural community. Targeted training should enable healthcare workers to prevent, accurately diagnose and manage these problems on site.
\end{abstract}

Keywords: Prevalence; Community; Skin disease

\section{Introduction}

Skin diseases are one of the most ubiquitous health problems, affecting 1 in 5 persons in the UK and 1 in 3 in the US, but there are large differences between countries, climates and cultures. The highest prevalence has been reported from developing countries and poor areas. In the mountainous region of northern India, the overall prevalence is $45.3 \% 5$, while, in rural Sumatra, it is $28.2 \%$. In Africa, reported prevalence figures vary between $11.7 \%$ in Bamako, Mali, to $48 \%$ in rural Ethiopia .The published prevalence figures in children are also high, 32\% in Kenya, 34\% in Mali, 31.3\% in Hong Kong and $38.8 \%$ in northern India. Figures of this kind reported from various countries are difficult to compare due to differences in study design, the seasonality of certain diseases and uncertainty in terms of census statistics [1].

A major reason for targeting skin diseases in the developing world is that the majority are transmissible and therefore potentially preventable and controllable. Most of the available statistics on the pattern of skin diseases have been based on hospital or private practice, and can provide a very crude indication of true prevalence and incidence in a community, as many social and economic factors affect the decision to seek medical advice. So, the present study was designed to determine the actual extent of the skin disease problem in rural areas [2].

\section{Methods}

It was a community survey. All community members consulting for skin problems at the health camp were examined. The majority of diagnoses were based on the patient's history and clinical signs. Those with recurrent or long lasting SDs were interviewed about symptoms, feelings, daily activities, wearing clothes, social/leisure activities, sport, work/school, personal relationships, sexual activity and treatment. The demographic and clinical data were documented on patient record forms prepared for the study.

\section{Data Analysis}

The data were entered in the SPSS 20.0 program and analyzed.

Result

Table 1: Patients with skin diseases.

\begin{tabular}{|c|c|}
\hline Gender & N \\
\hline Males & 199 \\
\hline Females & 252 \\
\hline Total & 451 \\
\hline
\end{tabular}


Table 2: Age groups.

\begin{tabular}{|c|c|c|}
\hline Age Group & Frequency & Percentage \\
\hline $0-10$ & 156 & $34.70 \%$ \\
\hline Nov-20 & 108 & $24.00 \%$ \\
\hline $21-30$ & 79 & $17.55 \%$ \\
\hline $31-40$ & 54 & $12.00 \%$ \\
\hline $41-50$ & 32 & $7.11 \%$ \\
\hline $51-60$ & 12 & $2.67 \%$ \\
\hline$>60$ & 9 & $1.99 \%$ \\
\hline Total & 451 & $100.00 \%$ \\
\hline
\end{tabular}

Table 3: Skin diseases and prevalence (Total population is 2000).

\begin{tabular}{|c|c|c|}
\hline Diagnosis & No of Cases & Prevalence \\
\hline Eczema & 182 & $9.10 \%$ \\
\hline Fungal infection & 93 & $4.65 \%$ \\
\hline Pigment disorders & 54 & $2.70 \%$ \\
\hline Acne & 38 & $1.90 \%$ \\
\hline Benign skin tumors & 19 & $0.95 \%$ \\
\hline Neurological & 18 & $0.90 \%$ \\
\hline Bacterial infection & 12 & $0.60 \%$ \\
\hline Oral/mucosal & 12 & $0.60 \%$ \\
\hline Miscellaneous & 23 & $1.20 \%$ \\
\hline Total & 451 & $22.50 \%$ \\
\hline
\end{tabular}

Out of total 2000 community members, six hundred presented for the health survey. A total of 451 patients had one or other form of disease yielding an overall prevalence rate of $22.5 \%$ (Table 1-3).

\section{Discussion}

The overall prevalence of skin diseases in this study was $22.5 \%$. As in many other studies from developing countries, children and females were more vulnerable than males. One fifth of the inhabitants affected is a fairly high prevalence for SDs, but it is considerably lower than what has been reported from other developing countries in Asia and Africa [3-7]. Eczemas, including photodermatitis, were the most common SDs in our study. The similar findings were obtained by Griils et al. [3] \& Saw et al. [4]. The number of infections and infestations were surprisingly low in the studied community. In northern India, infections and infestations accounted for 33\% [3], in Sumatra 49.5\% [4] and in Ethiopia 79\% [7]. This difference might be due to the fact that our study was conducted during a relatively cool season and it is well known that there are large seasonal variations in the incidence of skin diseases, especially infectious skin diseases', which are more common in tropical and subtropical climate zones.

\section{Conclusion}

Skin diseases are common in the rural communities. With the limited resources available and the lack of dermatologists in rural areas, we are convinced that information and training for healthcare workers will be a cost-effective way to prevent, diagnose, treat or refer these most common skin problems on site.

\section{Ethical Considerations}

For the Household survey and the interviews, verbal consent was obtained. All patients were provided with free consultations and medicines.

\section{References}

1. Shrestha DP, Gurung D, Rosdahl I (2012) Prevalence of skin diseases and impact on quality of life in hilly region of Nepal. Journal of Institute of Medicine 34(3): 44-49.

2. Abdel H, Abdel-Aty MA, Hofny ER (2003) Prevalence of skin diseases in rural areas of Assiut Governorate, Upper Egypt. Int J Dermatol 42(11): 887-892.

3. Grills N, Grills C, Spelman T, Stoove M, Hellard M, et al. (2012) Prevalence survey of dermatological conditions in mountainous north India. Int J Dermatol 51(5): 579-587.

4. Saw SM, Kohl D, Adjan MR, Wong ML, Hong CY, et al. (2001) A population based prevalence survey of skin diseases in adolescents and adults in rural Sumatra, Indonesia, 1999. Trans R Soc Trop Med Hyg 95(4): 384-388.

5. Gibbs S (1996) Skin disease and socioeconomic conditions in rural Africa: Tanzania. Int J Dermatol 35(9): 633-639.

6. Satimia FT, McBride SR, Leppard B (1998) Prevalence of skin disease in rural Tanzania and factors influencing the choice of health care, modern or traditional. Arch Dermatol 134(11): 1363-1366.

7. Figueroa JI, Fuller LC, Abraha A, Hay RJ (1998) Dermatology in South Western Ethopia: Rationale for a community approach. Int J Dermatol 37(10): 752-758.
Creative Commons Attribution 4.0 International License

For possible submissions Click Here

\section{Submit Article}

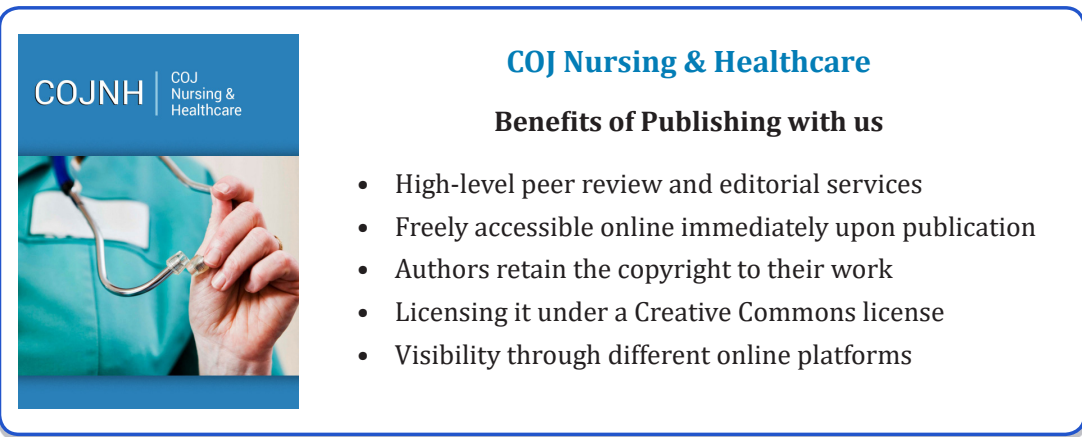

